\title{
An Inventory Model under Trapezoidal Type Demand, Weibull-Distributed Deterioration, and Partial Backlogging
}

\author{
Lianxia Zhao \\ School of Management, Shanghai University, Shanghai 200444, China \\ Correspondence should be addressed to Lianxia Zhao; zhaolianxia@staff.shu.edu.cn \\ Received 7 November 2013; Revised 19 January 2014; Accepted 21 January 2014; Published 6 March 2014 \\ Academic Editor: Nachamada Blamah \\ Copyright (C) 2014 Lianxia Zhao. This is an open access article distributed under the Creative Commons Attribution License, which \\ permits unrestricted use, distribution, and reproduction in any medium, provided the original work is properly cited.

\begin{abstract}
This paper studies an inventory model for Weibull-distributed deterioration items with trapezoidal type demand rate, in which shortages are allowed and partially backlogging depends on the waiting time for the next replenishment. The inventory models starting with no shortage is are to be discussed, and an optimal inventory replenishment policy of the model is proposed. Finally, numerical examples are provided to illustrate the theoretical results, and a sensitivity analysis of the major parameters with respect to the optimal solution is also carried out.
\end{abstract}

\section{Introduction}

The effect of deteriorating for items cannot be disregarded in many inventory systems and it is a general phenomenon in real life. Deterioration is defined as any process that decreases the usefulness or the value of the original item, such as decay or physical depletion. For example, fruits, vegetables, or foodstuffs are subject to spoilage directly while being kept in store, and electronic products, radioactive substances, and photographic film deteriorate through a gradual loss of potential or utility with the passage of time.

Due to the variability in economic circumstances, the basic assumptions of the EOQ model should be constantly modified according to the studied inventory model. In recent years, many researchers have studied kinds of EOQ models for deteriorating items. Ghare and Schrader [1] established the classical no-shortage inventory model with a constant rate of decay. Wu et al. [2] studied an inventory model with a Weibull-distributed deteriorating rate for items and assumed the demand rate with a continuous function of time. Wee [3] developed an inventory model with quantity discount, pricing, and partial backordering when the product in stock deteriorates with time. Related literature also includes Skouri and Papachristos [4], Wee [5], and Dye et al. [6].

practically, the demand rate of deterioration items is impossible to increase continuously all the time. Hill [7] proposed an inventory model with ramp type demand rate. Mandal and Pal [8] extended the inventory model with ramp type demand for deterioration items and allowed shortage. Wu [9] considered an inventory model with Weibull distribution deterioration and ramp type demand rate in which shortages are allowed and the backlogging rate is dependent on waiting time. Giri et al. [10] extended the ramp type demand inventory model with a more generalized Weibull deterioration distribution. Manna and Chaudhuri [11] developed an inventory model for time-dependent deteriorating items with ramp type demand rate. Skouri et al. [12] considered an inventory model with general ramp type demand rate, partial backlogging, and Weibull deterioration rate. Hung [13] extended their inventory model from ramp type demand rate and Weibull deterioration rate to arbitrary demand rate and arbitrary deterioration rate. Kumar et al. [14] studied fuzzy EOQ models with ramp type demand rate, partial backlogging, and time-dependent deterioration rat. Cheng et al. [15] considered an inventory model for time-dependent deteriorating items with trapezoidal type demand rate and partial backlogging. Uthayakumar and Rameswari [16] studied an inventory model for defective items with trapezoidal type demand rate to determine the optimal product reliability. Tan and Weng [17] considered a discrete-in-time inventory model for deteriorating items with partially backlogged. Ahmed et al. [18] proposed a method for 
finding the economic order quantity for an inventory model with ramp type demand rate, partial backlogging, and general deterioration rate. Lin [19] explored the inventory model with a general demand rate in which both the Weibull-distributed deterioration and partial backlogging are considered.

In the above mentioned research, one of assumptions was considered: the ramp type demand rate, partial backlogging, and Weibull-distributed deterioration rate. However, for fashionable commodities, high-tech products, and other short life cycle products, the demand rate should increase with the time up to certain point at first stage then reach a stabilized period and finally the demand rate decrease to zero and the products retreat from market in their product life cycle, that is, the demand rate with continuous trapezoidal function of time. On the other hand, in many real situations, customers encountering shortages will respond differently. Some customers are willing to wait until the next replenishment, while others may be impatient and go elsewhere as waiting time increases; that is, the willingness for a customer to wait for backlogging is diminishing with the length of the waiting time. In this paper, we consider an inventory model with Weibull-distributed deterioration items, trapezoidal type demand rate, and time-dependent partial backlogging. By analyzing the inventory model, a useful inventory replenishment policy is proposed. Finally, numerical examples are provided to illustrate the theoretical results, and a sensitivity analysis of the optimal solution with respect to major parameters is also carried out.

The rest of the paper is organized as follows. Section 2 describes the notation and assumptions used throughout this paper. Section 3 analyzes the inventory model, and some numerical examples to illustrate the solution procedure are provided. Sensitivity analysis of the major parameters is also carried out in Section 4, and the final Section concludes this paper.

\section{Notations and Assumptions}

The fundamental notations and assumptions used in inventory model and considered in this paper are given as below.

(i) $I(t)$ the level of inventory at time $t, 0 \leq t \leq T$.

(ii) $T$ the fixed length of each ordering cycle.

(iii) $t_{1}$ the time when the inventory level reaches zero for the inventory model.

(iv) $t_{1}^{*}$ the optimal point.

(v) $S$ the maximum inventory level for each ordering cycle.

(vi) $Q^{*}$ the optimal ordering quantity.

(vii) $A_{0}$ the fixed cost per order.

(viii) $c_{1}$ the cost of each deteriorated item.

(ix) $c_{2}$ the inventory holding cost per unit per unit of time.

(x) $c_{3}$ the shortage cost per unit per unit of time.

(xi) $c_{4}$ the lost sales cost per unit.

(xii) $C_{i}\left(t_{1}\right) i=1,2,3$, the average total cost per unit time under different conditions, respectively. (xiii) $T C\left(t_{1}\right)$ the average total cost per unit time.

(xiv) The demand rate, $D(t)$, which is positive and consecutive, is assumed to be a trapezoidal type function of time; that is,

$$
D(t)= \begin{cases}f(t), & t \leq \mu_{1} ; \\ D_{0}, & \mu_{1}<t<\mu_{2} ; \\ g(t), & \mu_{2} \leq t<T,\end{cases}
$$

where $\mu_{1}$ is time point changing from the increasing demand function $f(t)$ to constant demand $D_{0}$, and $\mu_{2}$ is time point changing from the constant demand $D_{0}$ to the decreasing demand function $g(t)$.

(xv) The replenishment rate is infinite; that is, replenishment is instantaneous.

(xvi) The deterioration rate of the item is defined as Weibull $(\alpha, \beta)$; that is the deterioration rate is $\theta(t)=$ $\alpha \beta t^{\beta-1}(\alpha>0, \beta>0, t>0)$.

(xvii) Shortages are allowed and they adopt the notation used in Abad [20], where the unsatisfied demand is backlogged and the fraction of shortages backordered is $e^{-\delta t}$, where $t$ is the waiting time up to the next replenishment. We also assume that $t e^{-\delta t}$ is an increasing function, which had appeared in Skouri et al. [12].

(xviii) The time horizon of the inventory model is finite.

\section{Model Formulation}

In this section, we consider an inventory model starting with no shortage. The behavior of the model during a given cycle is depicted in Figure 1. Replenishment occurs at time $t=0$ and the inventory level attains its maximum. From $t=0$ to $t_{1}$, the inventory level reduces due to demand and deterioration. At $t_{1}$, the inventory level achieves zero, then shortage is allowed to occur during the time interval $\left(t_{1}, T\right)$, and all of the demand during the shortage period $\left(t_{1}, T\right)$ is partially backlogged. According to the notations and assumptions mentioned above, the behavior of the model at any time can be described by the following differential equations:

$$
\frac{d I(t)}{d t}= \begin{cases}-\theta(t) I(t)-D(t), & 0<t<t_{1} ; \\ -e^{-\delta(T-t)} D(t), & t_{1}<t<T,\end{cases}
$$

with boundary conditions $I(0)=S, I\left(t_{1}\right)=0$.

In the following, we consider three possible cases based on the values of $t_{1}, \mu_{1}$, and $\mu_{2}$. These three cases are shown.

Case $1\left(0<t_{1} \leq \mu_{1}\right)$. Due to the deteriorating and trapezoidal type demand rate, the inventory level gradually diminishes during the time interval $\left[0, t_{1}\right]$ and ultimately falls to zero at time $t_{1}$. Thus, from (2), we have

$$
\frac{d I(t)}{d t}= \begin{cases}-\alpha \beta t^{\beta-1} I(t)-f(t), & 0<t<t_{1} ; \\ -e^{-\delta(T-t)} f(t), & t_{1}<t<\mu_{1} ; \\ -e^{-\delta(T-t)} D_{0}, & \mu_{1}<t<\mu_{2} ; \\ -e^{-\delta(T-t)} g(t), & \mu_{2}<t<T .\end{cases}
$$




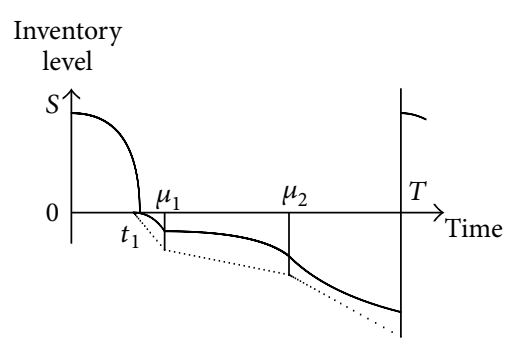

Case $1.0<t_{1} \leq \mu_{1}$

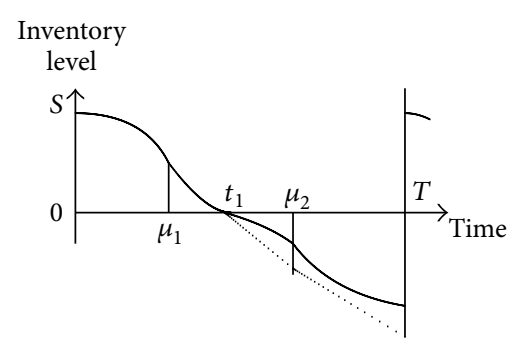

Case 2. $\mu_{1} \leq t_{1} \leq \mu_{2}$

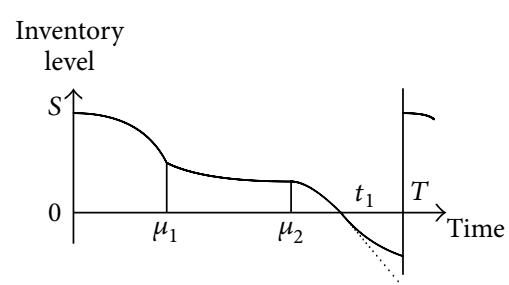

Case 3. $\mu_{2} \leq t_{1}<T$

FIGURE 1: Graphical representation of inventory level over the cycle.

By using the boundary condition $I\left(t_{1}\right)=0$, the solutions of (3) are given by

$$
I(t)=\left\{\begin{array}{cc}
\int_{t}^{t_{1}} f(x) e^{\alpha\left(x^{\beta}-t^{\beta}\right)} d x, & 0<t<t_{1} ; \\
-\int_{t_{1}}^{t} e^{\delta(x-T)} f(x) d x, & t_{1}<t<\mu_{1} \\
\frac{D_{0}}{\delta}\left(e^{\delta\left(\mu_{1}-T\right)}-e^{\delta(t-T)}\right) & \mu_{1}<t<\mu_{2} ; \\
-\int_{t_{1}}^{\mu_{1}} e^{\delta(x-T)} f(x) d x, & \\
-\int_{\mu_{2}}^{t} g(x) e^{\delta(x-T)} d x & \\
+\frac{D_{0}}{\delta}\left(e^{\delta\left(\mu_{1}-T\right)}-e^{\delta\left(\mu_{2}-T\right)}\right) & \\
-\int_{t_{1}}^{\mu_{1}} e^{\delta(x-T)} f(x) d x, & \mu_{2}<t<T .
\end{array}\right.
$$

The maximum inventory level per cycle is

$$
S=I(0)=\int_{0}^{t_{1}} f(x) e^{\alpha x^{\beta}} d x
$$

Then, the total number of deteriorated items $D_{T}$ in the interval $\left[0, t_{1}\right]$ is

$$
D_{T}=S-\int_{0}^{t_{1}} D(t) d t=\int_{0}^{t_{1}} f(x)\left(e^{\alpha x^{\beta}}-1\right) d x
$$

The total number of inventory $H_{T}$ carried during the interval $\left[0, t_{1}\right]$ is

$$
H_{T}=\int_{0}^{t_{1}} I(t) d t=\int_{0}^{t_{1}} \int_{t}^{t_{1}} f(x) e^{\alpha\left(x^{\beta}-t^{\beta}\right)} d x d t
$$

The total shortage quantity $B_{T}$ during the interval $\left[t_{1}, T\right]$ is

$$
\begin{aligned}
B_{T}= & -\int_{t_{1}}^{T} I(t) d t \\
= & \int_{t_{1}}^{\mu_{1}}\left[\int_{t_{1}}^{t} e^{\delta(x-T)} f(x) d x\right] d t \\
& -\int_{\mu_{1}}^{\mu_{2}}\left[\frac{D_{0}}{\delta}\left(e^{\delta\left(\mu_{1}-T\right)}-e^{\delta(t-T)}\right)\right. \\
& +\int_{\mu_{2}}^{T}\left[\int_{\mu_{2}}^{t} e^{\delta(x-T)} g(x) d x\right. \\
& \quad-\frac{D_{0}}{\delta}\left(e^{\delta\left(\mu_{1}-T\right)}-e^{\delta\left(\mu_{2}-T\right)}\right) \\
& +\frac{D_{0}}{\delta}\left[\left(T-\mu_{2}\right) d x\right] d t \\
& +\int_{\mu_{2}}^{T}(T-t) e^{\delta(t-T)} g(t) d t \\
= & \int_{t_{1}}^{\mu_{1}}(T-t) e^{\delta(t-T)} f(t) d t \\
D_{t_{1}} & \\
& \\
& \\
& \\
& \\
& \\
&
\end{aligned}
$$

The total of lost sales $L_{T}$ during the interval $\left[t_{1}, T\right]$ is

$$
\begin{aligned}
L_{T}= & \int_{t_{1}}^{\mu_{1}}\left(1-e^{\delta(t-T)}\right) f(t) d t+\int_{\mu_{1}}^{\mu_{2}}\left(1-e^{\delta(t-T)}\right) D_{0} d t \\
& +\int_{\mu_{2}}^{T}\left(1-e^{\delta(t-T)}\right) g(t) d t .
\end{aligned}
$$


Therefore, the average total cost per unit time under the condition $t_{1} \leq \mu_{1}$ can be given by

$$
\begin{aligned}
C_{1}\left(t_{1}\right)=\frac{1}{T}\left[A_{0}+c_{1} D_{T}+c_{2} H_{T}+c_{3} B_{T}+c_{4} L_{T}\right] \\
=\frac{1}{T}\left\{A_{0}+c_{1} \int_{0}^{t_{1}} f(x)\left(e^{\alpha x^{\beta}}-1\right) d x\right. \\
+c_{2} \int_{0}^{t_{1}} \int_{t}^{t_{1}} f(x) e^{\alpha\left(x^{\beta}-t^{\beta}\right)} d x d t \\
+c_{4}\left[\int_{t_{1}}^{\mu_{1}}\left(1-e^{\delta(t-T)}\right) f(t) d t\right. \\
+\int_{\mu_{1}}^{\mu_{2}}\left(1-e^{\delta(t-T)}\right) D_{0} d t \\
\left.+\int_{\mu_{2}}^{T}\left(1-e^{\delta(t-T)}\right) g(t) d t\right] \\
+c_{3}\left[\int_{t_{1}}^{\mu_{1}} e^{\delta(t-T)}(T-t) f(t) d t\right. \\
+\int_{\mu_{2}}^{T} e^{\delta(t-T)}(T-t) g(t) d t \\
+\frac{D_{0}}{\delta^{2}}\left(e^{\delta\left(\mu_{2}-T\right)}-e^{\delta\left(\mu_{1}-T\right)}\right) \\
+\frac{D_{0}}{\delta}\left(\left(T-\mu_{2}\right) e^{\delta\left(\mu_{2}-T\right)}\right. \\
\left.\left.\left.\left.+\mu_{1}\right) e^{\delta\left(\mu_{1}-T\right)}\right)\right]\right\}
\end{aligned}
$$

Case $2\left(\mu_{1} \leq t_{1} \leq \mu_{2}\right)$. The differential equations governing the inventory model can be expressed as follows:

$$
\frac{d I(t)}{d t}= \begin{cases}-\alpha \beta t^{\beta-1} I(t)-f(t), & 0<t<\mu_{1} \\ -\alpha \beta t^{\beta-1} I(t)-D_{0}, & \mu_{1}<t<t_{1} \\ -e^{-\delta(T-t)} D_{0}, & t_{1}<t<\mu_{2} \\ -e^{-\delta(T-t)} g(t), & \mu_{2}<t<T .\end{cases}
$$

Solving the differential equation (11) with $I\left(t_{1}\right)=0$, we have

$$
I(t)=\left\{\begin{aligned}
\int_{t}^{\mu_{1}} f(x) e^{\alpha\left(x^{\beta}-t^{\beta}\right)} d x & \\
\quad+D_{0} \int_{\mu_{1}}^{t_{1}} e^{\alpha\left(x^{\beta}-t^{\beta}\right)} d x, & 0<t<\mu_{1} ; \\
D_{0} \int_{t}^{t_{1}} e^{\alpha\left(x^{\beta}-t^{\beta}\right)} d x, & \mu_{1}<t<t_{1} \\
\frac{D_{0}}{\delta}\left(e^{\delta\left(t_{1}-T\right)}-e^{\delta(t-T)}\right), & t_{1}<t<\mu_{2} ; \\
-\int_{\mu_{2}}^{t} e^{\delta(x-T)} g(x) d x & \\
\quad+\frac{D_{0}}{\delta}\left(e^{\delta\left(t_{1}-T\right)}-e^{\delta\left(\mu_{2}-T\right)}\right), & \mu_{2}<t<T .
\end{aligned}\right.
$$

The beginning inventory level can be computed as

$$
S=I(0)=\int_{0}^{\mu_{1}} f(x) e^{\alpha x^{\beta}} d x+D_{0} \int_{\mu_{1}}^{t_{1}} e^{\alpha x^{\beta}} d x
$$

The total number of items which perish in the interval $\left[0, t_{1}\right]$ is

$$
D_{T}=\int_{0}^{\mu_{1}} f(x)\left(e^{\alpha x^{\beta}}-1\right) d x+D_{0} \int_{\mu_{1}}^{t_{1}}\left(e^{\alpha x^{\beta}}-1\right) d x .
$$

The total number of inventory carried during the interval $\left[0, t_{1}\right]$ is

$$
H_{T}=\int_{0}^{\mu_{1}} \int_{t}^{\mu_{1}} e^{\alpha\left(x^{\beta}-t^{\beta}\right)} f(x) d x d t+D_{0} \int_{\mu_{1}}^{t_{1}} \int_{t}^{t_{1}} e^{\alpha\left(x^{\beta}-t^{\beta}\right)} d x d t
$$

The total shortage quantity during the interval $\left[t_{1}, T\right]$ is

$$
\begin{aligned}
& B_{T}=\int_{\mu_{2}}^{T}(T-t) e^{\delta(t-T)} g(t) d t \\
&+\frac{D_{0}}{\delta}\left[e^{\delta\left(t_{1}-T\right)}\left(T-t_{1}+\frac{1}{\delta}\right)\right. \\
&\left.\quad-e^{-\delta\left(\mu_{2}-T\right)}\left(T-\mu_{2}+\frac{1}{\delta}\right)\right] .
\end{aligned}
$$

The total of lost sales during the interval $\left[t_{1}, T\right]$ is

$$
L_{T}=D_{0} \int_{t_{1}}^{\mu_{2}}\left(1-e^{\delta(t-T)}\right) d t+\int_{\mu_{2}}^{T}\left(1-e^{\delta(t-T)}\right) g(t) d t .
$$

Therefore, the average total cost per unit time under the condition $\mu_{1} \leq t_{1} \leq \mu_{2}$ can be given by

$$
\begin{array}{r}
C_{2}\left(t_{1}\right)=\frac{1}{T}\left[A_{0}+c_{1} D_{T}+c_{2} H_{T}+c_{3} B_{T}+c_{4} L_{T}\right] \\
=\frac{1}{T}\left\{A_{0}+c_{1}\left[\int_{0}^{\mu_{1}} f(x)\left(e^{\alpha x^{\beta}}-1\right) d x\right.\right. \\
\left.+D_{0} \int_{\mu_{1}}^{t_{1}}\left(e^{\alpha x^{\beta}}-1\right) d x\right] \\
+c_{2}\left[\int_{0}^{\mu_{1}} \int_{t}^{\mu_{1}} e^{\alpha\left(x^{\beta}-t^{\beta}\right)} f(x) d x d t\right. \\
\left.+D_{0} \int_{0}^{t_{1}} \int_{t}^{t_{1}} e^{\alpha\left(x^{\beta}-t^{\beta}\right)} d x d t\right]
\end{array}
$$




$$
\begin{gathered}
+c_{3}\left[\int_{\mu_{2}}^{T}(T-t) e^{\delta(t-T)} g(t) d t\right. \\
+\frac{D_{0}}{\delta}\left(e^{\delta\left(t_{1}-T\right)}\left(T-t_{1}+\frac{1}{\delta}\right)\right. \\
\left.\left.-e^{\delta\left(\mu_{2}-T\right)}\left(T-\mu_{2}+\frac{1}{\delta}\right)\right)\right] \\
+c_{4}\left[D_{0} \int_{t_{1}}^{\mu_{2}}\left(1-e^{\delta(t-T)}\right) d t\right. \\
\left.\left.+\int_{\mu_{2}}^{T}\left(1-e^{\delta(t-T)}\right) g(t) d t\right]\right\} .
\end{gathered}
$$

Case $3\left(\mu_{2} \leq t_{1}<T\right)$. The differential equations governing the inventory model can be expressed as follows:

$$
\frac{d I(t)}{d t}= \begin{cases}-\alpha \beta t^{\beta-1} I(t)-f(t), & 0<t<\mu_{1} ; \\ -\alpha \beta t^{\beta-1} I(t)-D_{0}, & \mu_{1}<t<\mu_{2} \\ -\alpha \beta t^{\beta-1} I(t)-g(t), & \mu_{2}<t<t_{1} \\ -e^{-\delta(T-t)} g(t), & t_{1}<t<T\end{cases}
$$

(18) Solving the differential equation (19) with $I\left(t_{1}\right)=0$, we have

$$
I(t)= \begin{cases}\int_{t}^{\mu_{1}} e^{\alpha\left(x^{\beta}-t^{\beta}\right)} f(x) d x+D_{0} \int_{\mu_{1}}^{\mu_{2}} e^{\alpha\left(x^{\beta}-t^{\beta}\right)} d x+\int_{\mu_{2}}^{t_{1}} e^{\alpha\left(x^{\beta}-t^{\beta}\right)} g(x) d x, & 0<t<\mu_{1} \\ D_{0} \int_{t}^{\mu_{2}} e^{\alpha\left(x^{\beta}-t^{\beta}\right)} d x+\int_{\mu_{2}}^{t_{1}} e^{\alpha\left(x^{\beta}-t^{\beta}\right)} g(x) d x, & \mu_{1}<t<\mu_{2} \\ \int_{t}^{t_{1}} e^{\alpha\left(x^{\beta}-t^{\beta}\right)} g(x) d x, & \mu_{2}<t<t_{1} \\ -\int_{t_{1}}^{t} e^{\delta(x-T)} g(x) d x, & t_{1}<t<T .\end{cases}
$$

The beginning inventory level can be computed as

$$
\begin{aligned}
S= & I(0) \\
= & \int_{0}^{\mu_{1}} e^{\alpha x^{\beta}} f(x) d x \\
& +D_{0} \int_{\mu_{1}}^{\mu_{2}} e^{\alpha x^{\beta}} d x+\int_{\mu_{2}}^{t_{1}} e^{\alpha x^{\beta}} g(x) d x .
\end{aligned}
$$

The total number of items which perish in the interval $\left[0, t_{1}\right]$ is

$$
\begin{aligned}
D_{T}= & \int_{0}^{\mu_{1}}\left(e^{\alpha x^{\beta}}-1\right) f(x) d x+D_{0} \int_{\mu_{1}}^{\mu_{2}}\left(e^{\alpha x^{\beta}}-1\right) d x \\
& +\int_{\mu_{2}}^{t_{1}}\left(e^{\alpha x^{\beta}}-1\right) g(x) d x .
\end{aligned}
$$

The total number of inventory carried during the interval $\left[0, t_{1}\right]$ is

$$
\begin{aligned}
& +\int_{0}^{\mu_{2}} \int_{\mu_{2}}^{t_{1}} e^{\alpha\left(x^{\beta}-t^{\beta}\right)} g(x) d x d t \\
& +\int_{\mu_{2}}^{t_{1}} \int_{t}^{t_{1}} e^{\alpha\left(x^{\beta}-t^{\beta}\right)} g(x) d x d t .
\end{aligned}
$$

The total shortage quantity during the interval $\left[t_{1}, T\right]$ is

$$
B_{T}=\int_{t_{1}}^{T}(T-t) e^{-\delta(T-t)} g(t) d t
$$

The total of lost sales during the interval $\left[t_{1}, T\right]$ is

$$
L_{T}=\int_{t_{1}}^{T}\left(1-e^{-\delta(T-t)}\right) g(t) d t .
$$

Therefore, the average total cost per unit time under the condition $\mu_{2} \leq t_{1} \leq T$ can be given by

$$
\begin{array}{r}
C_{3}\left(t_{1}\right)=\frac{1}{T}\left[A_{0}+c_{1} D_{T}+c_{2} H_{T}+c_{3} B_{T}+c_{4} L_{T}\right] \\
=\frac{1}{T}\left\{A_{0}+c_{1}\left[\int_{0}^{\mu_{1}}\left(e^{\alpha x^{\beta}}-1\right) f(x) d x\right.\right. \\
+D_{0} \int_{\mu_{1}}^{\mu_{2}}\left(e^{\alpha x^{\beta}}-1\right) d x \\
\left.+\int_{\mu_{2}}^{t_{1}}\left(e^{\alpha x^{\beta}}-1\right) g(x) d x\right]
\end{array}
$$




$$
\begin{gathered}
+c_{2}\left[\int_{0}^{\mu_{1}} \int_{t}^{\mu_{1}} e^{\alpha\left(x^{\beta}-t^{\beta}\right)} f(x) d x d t\right. \\
+D_{0} \int_{0}^{\mu_{1}} \int_{\mu_{1}}^{\mu_{2}} e^{\alpha\left(x^{\beta}-t^{\beta}\right)} d x d t \\
+D_{0} \int_{\mu_{1}}^{\mu_{2}} \int_{t}^{\mu_{2}} e^{\alpha\left(x^{\beta}-t^{\beta}\right)} d x d t \\
+\int_{0}^{\mu_{2}} \int_{\mu_{2}}^{t_{1}} e^{\alpha\left(x^{\beta}-t^{\beta}\right)} g(x) d x d t \\
\left.+\int_{\mu_{2}}^{t_{1}} \int_{t}^{t_{1}} e^{\alpha\left(x^{\beta}-t^{\beta}\right)} g(x) d x d t\right] \\
+c_{3}\left[\int_{t_{1}}^{T}(T-t) e^{\delta(t-T)} g(t) d t\right] \\
\left.+c_{4}\left[\int_{t_{1}}^{T}\left(1-e^{\delta(t-T)}\right) g(t) d t\right]\right\}
\end{gathered}
$$

From the above analysis, we obtain that the total average cost of the model over the time interval $[0, T]$ is

$$
T C\left(t_{1}\right)= \begin{cases}C_{1}\left(t_{1}\right), & 0<t_{1} \leq \mu_{1} \\ C_{2}\left(t_{1}\right), & \mu_{1}<t_{1} \leq \mu_{2} \\ C_{3}\left(t_{1}\right), & \mu_{2}<t_{1}<T\end{cases}
$$

where $C_{1}\left(t_{1}\right), C_{2}\left(t_{1}\right)$, and $C_{3}\left(t_{1}\right)$ are obtained from (10), (18), and (26), respectively.

In the following, we will provide the results which ensure the existence of a unique $t_{1}$, say $t_{1}^{*}$, so as to minimize the total average cost for the model system starting with no shortages.

If $0<t_{1} \leq \mu_{1}$, taking the first-order derivative of $C_{1}\left(t_{1}\right)$ with respect to $t_{1}$, we obtain

$$
\frac{d C_{1}\left(t_{1}\right)}{d t_{1}}=\frac{f\left(t_{1}\right)}{T} h\left(t_{1}\right)
$$

where

$$
\begin{aligned}
h\left(t_{1}\right)= & c_{1}\left(e^{\alpha t_{1}^{\beta}}-1\right) \\
& +c_{2} \int_{0}^{t_{1}} e^{\alpha\left(t_{1}^{\beta}-t^{\beta}\right)} d t+c_{3}\left(t_{1}-T\right) e^{\delta\left(t_{1}-T\right)} \\
& +c_{4}\left(e^{\delta\left(t_{1}-T\right)}-1\right),
\end{aligned}
$$

then we can obtain $h(0)<0$ and $h(T)>0$. By using the assumption ( $t e^{-\delta t}$ is an increasing function, where $t$ is the waiting time up to the next replenishment), we have

$$
\begin{aligned}
\frac{d h\left(t_{1}\right)}{d t_{1}}= & \alpha \beta t_{1}^{\beta-1}\left(c_{1} e^{\alpha t_{1}^{\beta}}+c_{2} \int_{0}^{t_{1}} e^{\alpha\left(t_{1}^{\beta}-t^{\beta}\right)} d t\right) \\
& +\left[c_{3}\left(\delta\left(t_{1}-T\right)+1\right)+c_{4} \delta\right] e^{\delta\left(t_{1}-T\right)}+c_{2}>0
\end{aligned}
$$

which implies that $h\left(t_{1}\right)$ is a strictly monotone increasing function. Therefore, the equation

$$
\begin{aligned}
h\left(t_{1}\right)= & c_{1}\left(e^{\alpha t_{1}^{\beta}}-1\right)+c_{2} \int_{0}^{t_{1}} e^{\alpha\left(t_{1}^{\beta}-t^{\beta}\right)} d t \\
& +c_{3}\left(t_{1}-T\right) e^{\delta\left(t_{1}-T\right)}+c_{4}\left(e^{\delta\left(t_{1}-T\right)}-1\right) \\
= & 0
\end{aligned}
$$

has a unique root $t_{1}^{*} \in(0, T)$ obtained by using Mathematica 9.0. Further, $t_{1}^{*}$ is the only zero-point of $d C_{1}\left(t_{1}\right) / d t_{1}=0$ since $f\left(t_{1}\right)>0$.

If $0<t_{1}^{*} \leq \mu_{1}$, for this $t_{1}^{*}$, we have

$$
\left.\frac{d^{2} C_{1}\left(t_{1}\right)}{d t_{1}^{2}}\right|_{t_{1}=t_{1}^{*}}=f\left(t_{1}^{*}\right) \frac{d h\left(t_{1}^{*}\right)}{T d t_{1}^{*}}>0,
$$

which means that the total average cost $C_{1}\left(t_{1}\right)$ can obtain its minimum value at $t_{1}^{*}$.

The optimal value of the order level, $S=I(0)$, is

$$
S^{*}=\int_{0}^{t_{1}^{*}} f(x) e^{\alpha x^{\beta}} d x
$$

and the optimal order quantity $Q^{*}$ is

$$
\begin{aligned}
Q^{*}= & S^{*}+\int_{t_{1}^{*}}^{\mu_{1}} e^{\delta(t-T)} f(t) d t \\
& +D_{0} \int_{\mu_{1}}^{\mu_{2}} e^{\delta(t-T)} d t+\int_{\mu_{2}}^{T} e^{\delta(t-T)} g(t) d t .
\end{aligned}
$$

If $t_{1}^{*} \geq \mu_{1}$, then the optimal value of $C_{1}\left(t_{1}\right)$ is obtained at $t_{1}=\mu_{1}$.

If $\mu_{1}<t_{1} \leq \mu_{2}$, taking the first-order and second-order derivative of $C_{2}\left(t_{1}\right)$ with respect to $t_{1}$, respectively, we obtain

$$
\frac{d C_{2}\left(t_{1}\right)}{d t_{1}}=\frac{D_{0}}{T} h\left(t_{1}\right)
$$

If $\mu_{1}<t_{1}^{*} \leq \mu_{2}$, for this $t_{1}^{*}$, we have

$$
\left.\frac{d^{2} C_{2}\left(t_{1}\right)}{d t_{1}^{2}}\right|_{t_{1}=t_{1}^{*}}=D_{0} \frac{d h\left(t_{1}^{*}\right)}{T d t_{1}^{*}}>0
$$

where the function $h\left(t_{1}\right)$ is given by (31), and (36) implies that $C_{2}\left(t_{1}\right)$ is a strictly convex function in $t_{1}$ and obtained its minimum value at $t_{1}^{*}$. Therefore, the equation $h\left(t_{1}\right)=0$ has a unique root $t_{1}^{*}$ in $(0, T)$.

The optimal value of the order level, $S=I(0)$, is

$$
S^{*}=\int_{0}^{\mu_{1}} f(x) e^{\alpha x^{\beta}} d x+D_{0} \int_{\mu_{1}}^{t_{1}^{*}} e^{\alpha x^{\beta}} d x,
$$

and the optimal order quantity $Q^{*}$ is

$$
Q^{*}=S^{*}+\int_{t_{1}^{*}}^{\mu_{2}} e^{\delta(t-T)} D_{0} d t+\int_{\mu_{2}}^{T} e^{\delta(t-T)} g(t) d t
$$


If $t_{1}^{*} \leq \mu_{1}$, then the optimal value of $C_{2}\left(t_{1}\right)$ is obtained at $t_{1}^{*}=\mu_{1}$, and if $t_{1}^{*} \geq \mu_{2}$, then the optimal value of $C_{2}\left(t_{1}\right)$ is obtained at $t_{1}^{*}=\mu_{2}$.

If $\mu_{2}<t_{1} \leq T$, taking the first-order and second-order derivative of $C_{3}\left(t_{1}\right)$ with respect to $t_{1}$, respectively, we obtain

$$
\frac{d C_{3}\left(t_{1}\right)}{d t_{1}}=\frac{g\left(t_{1}\right)}{T} h\left(t_{1}\right) .
$$

If $\mu_{2}<t_{1}^{*} \leq T$, for this $t_{1}^{*}$, we have

$$
\left.\frac{d^{2} C_{3}\left(t_{1}\right)}{d t_{1}^{2}}\right|_{t_{1}=t_{1}^{*}}=g\left(t_{1}^{*}\right) \frac{d h\left(t_{1}^{*}\right)}{T d t_{1}^{*}}>0 .
$$

The function $h\left(t_{1}\right)$ is given by (31), and (40) implies that $C_{3}\left(t_{1}\right)$ can obtain its minimum value at $t_{1}^{*}$.

The optimal value of the order level, $S=I(0)$, is

$$
S^{*}=\int_{0}^{\mu_{1}} e^{\alpha x^{\beta}} f(x) d x+D_{0} \int_{\mu_{1}}^{\mu_{2}} e^{\alpha x^{\beta}} d x+\int_{\mu_{2}}^{t_{1}^{*}} e^{\alpha x^{\beta}} g(x) d x,
$$

and the optimal order quantity $Q^{*}$ is

$$
Q^{*}=S^{*}+\int_{t_{1}^{*}}^{T} e^{\delta(t-T)} g(t) d t .
$$

If $t_{1}^{*} \leq \mu_{2}$, then the optimal value of $C_{3}\left(t_{1}\right)$ is obtained at $t_{1}^{*}=\mu_{2}$.

The above analysis shows that the three average cost functions $C_{1}\left(t_{1}\right), C_{2}\left(t_{2}\right)$, and $C_{3}\left(t_{1}\right)$ can obtain their minimum value at $t_{1}^{*} \in(0, T)$ which is determined by (31). Therefore, based on the results analyzed above, this paper derives a procedure to locate the optimal replenishment policy starting with no shortage for the three cases. The procedure is as follows.

Step 1. Solve $t_{1}^{*}$ from (31).

Step 2. Compare $t_{1}^{*}$ to $\mu_{1}$ and $\mu_{2}$, respectively.

Step 2.1. If $t_{1}^{*} \in\left(0, \mu_{1}\right]$, then the optimal total average cost and the optimal order quantity can be obtained by (10) and (34), respectively.

Step 2.2. If $t_{1}^{*} \in\left(\mu_{1}, \mu_{2}\right]$, then the optimal total average cost and the optimal order quantity can be obtained by (18) and (38), respectively.

Step 2.3. If $t_{1}^{*} \in\left(\mu_{2}, T\right]$, then the optimal total average cost and the optimal order quantity can be obtained by (26) and (42), respectively.

Remark 1. In such considered inventory model starting with no shortage, if $t_{1}$ satisfies $\mu_{1}<t_{1} \leq T<\mu_{2}$, the considered inventory model reduces to that of Skouri et al. [12].

\section{Numerical Example}

In order to demonstrate the above procedure which can be applied to obtain the optimal solution of the model, this paper presents several examples for the model, respectively. Examples are based on piecewise demand rate, such as $f(t)=$ $a_{1}+b_{1} t$ and $g(t)=a_{2} e^{-b_{2} t}$.

Example 1. The parameter values are given as follows: $T=12$ weeks, $\mu_{1}=4$ weeks, $\mu_{2}=8$ weeks, $\alpha=0.005, \beta=2, \delta=0.04$, $a_{1}=30$ unit, $b_{1}=5$ unit, $a_{2}=100$ unit, $A_{0}=\$ 500, c_{1}=\$ 2$, $c_{2}=\$ 3, c_{3}=\$ 12$, and $c_{4}=\$ 8$.

The model starting with no shortage; by solving the equation $h\left(t_{1}\right)=0$, we have $t_{1}^{*}=8.7622$. From (42) and (26), we obtain $Q^{*}=582.5217$ and $T C\left(t_{1}^{*}\right)=793.9986$, respectively.

Example 2. The parameter values are given as follows: $T=12$ weeks, $\mu_{1}=4$ weeks, $\mu_{2}=8$ weeks, $\alpha=0.005, \beta=2, \delta=0.02$, $a_{1}=30$ unit, $b_{1}=5$ unit, $a_{2}=100$ unit, $A_{0}=\$ 500, c_{1}=\$ 5$, $c_{2}=\$ 10, c_{3}=\$ 12$, and $c_{4}=\$ 8$.

The model starting with no shortage, by solving the equation $h\left(t_{1}\right)=0$, we have $t_{1}^{*}=5.8330$. From (38) and (18), we obtain $Q^{*}=528.4725$ and $T C\left(t_{1}^{*}\right)=1601.4013$, respectively.

Example 3. The parameter values are given as follows: $T=12$ weeks, $\mu_{1}=4$ weeks, $\mu_{2}=6$ weeks, $\alpha=0.005, \beta=1.6$, $\delta=0.2, a_{1}=30$ unit, $b_{1}=5$ unit, $a_{2}=100$ unit, $A_{0}=\$ 500$, $c_{1}=\$ 5, c_{2}=\$ 10, c_{3}=\$ 12$, and $c_{4}=\$ 8$.

The model starting with no shortage, solving the equation $h\left(t_{1}\right)=0$, the optimal value of $t_{1}$ is $t_{1}^{*}=2.3235$. The optimal ordering quantity is $Q^{*}=272.6678$, and the minimum cost $T C\left(t_{1}^{*}\right)=1258.82$.

In order to clearly indicate the effects of parameters such as $\delta, \alpha, \beta, c_{1}, c_{2}, c_{3}$, and $c_{4}$ on the optimal on-hand inventory $S^{*}$, the optimal ordering quantity $Q^{*}$, and the optimal total $\operatorname{cost} T C\left(t_{1}^{*}\right)$, respectively, the paper will study the sensitivity of the optimal solution to changes in the value of different parameter associated with the studied inventory model. The sensitivity analysis is performed on the base of Example 1, and the results are shown in Table 1-7.

By studying the results of Table 1 , it is found that the shortage time $t_{1}^{*}$, inventory level $S^{*}$, order quantity $Q^{*}$, and the total average cost $T C\left(t_{1}^{*}\right)$ gradually decrease as the shortage parameter $\delta$ increases for the model, respectively. We also find that the percentage increase of $\delta$ from $14.3 \%$ to $100 \%$ causes $T C\left(t_{1}^{*}\right)$ to decrease from $0.45 \%$ to $0.34 \%$, $Q^{*}$ decrease from $0.75 \%$ to $0.52 \%, t_{1}^{*}$ decrease from $0.78 \%$ to $0.53 \%$, and $S^{*}$ decrease from $1.02 \%$ to $0.69 \%$. It is also observed that the value of $t_{1}^{*}, S^{*}, Q^{*}$, and $T C\left(t_{1}^{*}\right)$ all are lowly sensitive to the changes of $\delta$ for the considered inventory model.

By studying the results of Table 2 , it is found that $S^{*}, Q^{*}$, and $T C\left(t_{1}^{*}\right)$ coordinates to the deterioration parameter $\alpha$; the shortage time $t_{1}^{*}$ decreases as $\alpha$ increases for the model. It is also found that the percentage increase of $\alpha$ from 16.7\% to $100 \%$ causes $T C\left(t_{1}^{*}\right)$ to decrease by $2.066 \%-2.595 \%, Q^{*}$ to increase by $1.597 \%-2.44 \%$, the shortage time $t_{1}^{*}$ to decrease by $1.513 \%-1.455 \%$, and $S^{*}$ to increase by $0.917 \%-1.651 \%$. It also observes that the value of $t_{1}^{*}, S^{*}, Q^{*}$, and $T C\left(t_{1}^{*}\right)$ all are moderately sensitive to the changes of $\alpha$ for the considered inventory model. 
TABLE 1: The sensitivity of $\delta$ for the models in Example 1.

\begin{tabular}{lccccccccc}
\hline$\delta$ & 0 & 0.01 & 0.02 & 0.03 & 0.04 & 0.05 & 0.06 & 0.07 & 0.08 \\
\hline$t_{1}^{*}$ & 8.9664 & 8.9187 & 8.8689 & 8.8167 & 8.7622 & 8.7049 & 8.6449 & 8.5817 & 8.5152 \\
$S^{*}$ & 472.9889 & 469.7083 & 466.2823 & 462.7001 & 458.9498 & 455.0167 & 450.8910 & 446.5519 & 441.9829 \\
$Q^{*}$ & 595.6569 & 592.5872 & 589.3822 & 586.0308 & 582.5217 & 578.8412 & 574.9771 & 570.9112 & 566.6265 \\
$\mathrm{TC}\left(t_{1}^{*}\right)$ & 805.6323 & 802.8699 & 800.0139 & 797.0588 & 793.9986 & 790.8268 & 787.5365 & 784.1200 & 780.5690 \\
\hline
\end{tabular}

TABLE 2: The sensitivity of $\alpha$ for the models in Example 1.

\begin{tabular}{lcccccccc}
\hline$\alpha$ & 0 & 0.001 & 0.002 & 0.003 & 0.004 & 0.005 & 0.006 & 0.007 \\
\hline$t_{1}^{*}$ & 9.4545 & 9.3115 & 9.1702 & 9.0312 & 8.8950 & 8.7622 & 8.6328 & 8.5072 \\
$S^{*}$ & 428.3286 & 435.4002 & 442.0048 & 448.1317 & 453.7785 & 458.9498 & 463.6555 & 467.9088 \\
$Q^{*}$ & 523.8866 & 536.6685 & 548.9558 & 560.7091 & 571.9025 & 582.5217 & 592.5618 & 602.0259 \\
$\mathrm{TC}\left(t_{1}^{*}\right)$ & 704.6045 & 722.8867 & 741.0107 & 758.9297 & 776.6035 & 793.9986 & 811.0872 & 827.8474 \\
\hline
\end{tabular}

TABLE 3: The sensitivity of $\beta$ for the models in Example 1.

\begin{tabular}{lcccccccc}
\hline$\beta$ & 1.4 & 1.6 & 1.8 & 2.0 & 2.2 & 2.4 & 2.6 & 2.8 \\
\hline$t_{1}^{*}$ & 9.2876 & 9.1810 & 9.0142 & 8.7622 & 8.4047 & 7.9422 & 7.4073 & 6.8496 \\
$S^{*}$ & 442.9058 & 447.5894 & 453.1802 & 458.9076 & 462.8345 & 461.6422 & 453.4686 & 438.8904 \\
$Q^{*}$ & 545.1340 & 554.1055 & 566.4485 & 582.4772 & 601.2274 & 774.6099 & 766.4364 & 751.8582 \\
$\mathrm{TC}\left(t_{1}^{*}\right)$ & 745.7703 & 764.3043 & 791.7624 & 790.7114 & 829.3653 & 588.7417 & 473.1282 & 391.1266 \\
\hline
\end{tabular}

TABLE 4: The sensitivity of $c_{1}$ for the models in Example 1.

\begin{tabular}{lccccccccc}
\hline$c_{1}$ & 0 & 0.4 & 1 & 1.6 & 2 & 2.4 & 2.6 & 3 & 3.6 \\
\hline$t_{1}^{*}$ & 8.8225 & 8.8103 & 8.7921 & 8.7741 & 8.7622 & 8.7503 & 8.7443 & 8.7326 & 8.7150 \\
$S^{*}$ & 463.0980 & 462.2595 & 461.0101 & 459.7707 & 458.9498 & 458.1333 & 457.7266 & 456.9164 & 455.7090 \\
$Q^{*}$ & 584.1909 & 583.8529 & 583.3499 & 582.8514 & 582.5217 & 582.1940 & 582.5217 & 581.7061 & 581.2226 \\
$\mathrm{TC}\left(t_{1}^{*}\right)$ & 783.5429 & 785.6518 & 788.7984 & 791.9251 & 793.9986 & 796.0633 & 797.0925 & 799.1443 & 802.2061 \\
\hline
\end{tabular}

TABLE 5: The sensitivity of $c_{2}$ for the model in Example 1.

\begin{tabular}{lccccccccc}
\hline$c_{2}$ & 0 & 0.4 & 0.8 & 1.2 & 1.8 & 2.4 & 3 & 3.4 & 3.8 \\
\hline$t_{1}^{*}$ & 11.8343 & 11.267 & 10.7698 & 10.326 & 9.7377 & 9.2216 & 8.7622 & 8.4819 & 8.2196 \\
$S^{*}$ & 673.7217 & 633.0852 & 597.9589 & 566.9228 & 526.1187 & 490.5382 & 458.9498 & 439.6922 & 421.6606 \\
$Q^{*}$ & 679.6039 & 659.4483 & 642.7261 & 628.4787 & 610.4744 & 595.4175 & 582.5217 & 574.8648 & 567.8284 \\
$\mathrm{TC}\left(t_{1}^{*}\right)$ & 67.2679 & 193.9216 & 308.8975 & 413.9636 & 555.8150 & 681.6692 & 793.9986 & 862.3253 & 925.9516 \\
\hline
\end{tabular}

TABLE 6: The sensitivity of $c_{3}$ for the models in Example 1.

\begin{tabular}{lccccccccc}
\hline$c_{3}$ & 10.4 & 10.6 & 10.8 & 11 & 11.2 & 11.6 & 12 & 12.4 & 12.8 \\
\hline$t_{1}^{*}$ & 8.4424 & 8.4859 & 8.5284 & 8.5698 & 8.6102 & 8.6879 & 8.7622 & 8.8329 & 8.9005 \\
$S^{*}$ & 436.9771 & 439.9713 & 442.889 & 445.7332 & 448.5071 & 453.854 & 458.9498 & 463.8114 & 468.4587 \\
$Q^{*}$ & 573.7973 & 574.9747 & 576.1255 & 577.2506 & 578.3509 & 580.4809 & 582.5217 & 584.4787 & 586.3587 \\
$\mathrm{TC}\left(t_{1}^{*}\right)$ & 763.8057 & 767.9203 & 771.9299 & 775.8387 & 779.6505 & 786.9976 & 793.9986 & 800.6779 & 807.0579 \\
\hline
\end{tabular}

TABLE 7: The sensitivity of $c_{4}$ for the models in Example 1.

\begin{tabular}{lccccccccc}
\hline$c_{4}$ & 0 & 2 & 4 & 6 & 8 & 10 & 12 & 14 \\
\hline$t_{1}^{*}$ & 8.6989 & 8.7150 & 8.7309 & 8.7466 & 8.7622 & 8.7775 & 8.7928 & 8.8078 & 8.82272 \\
$S^{*}$ & 454.6069 & 455.7103 & 456.8017 & 457.8815 & 458.9498 & 460.0048 & 461.0527 & 462.0877 & 463.1120 \\
$Q^{*}$ & 580.7818 & 581.2231 & 581.6601 & 582.0929 & 582.5217 & 582.9455 & 583.367 & 583.7837 & 584.1966 \\
$\mathrm{TC}\left(t_{1}^{*}\right)$ & 788.1626 & 789.6445 & 791.1109 & 792.5621 & 793.9986 & 795.4203 & 796.8276 & 798.2207 & 799.5999 \\
\hline
\end{tabular}


By studying the results of Table 3, it is found that $S^{*}$, $Q^{*}$, and $T C\left(t_{1}^{*}\right)$ coordinate to the deterioration parameter $\beta$, while the shortage time $t_{1}^{*}$ decreases as $\beta$ increases for the model. It is also found that the increase of $\beta$ from 1.4 to 2.2 causes $S^{*}$ to increase, while the increase of $\beta$ from 2.4 to 2.8 causes $S^{*}$ to decrease, $Q^{*}$ to increase by $2.44 \%-1.597 \%$, $T C\left(t_{1}^{*}\right)$ to increase by $2.595 \%-2.066 \%$, and the shortage time $t_{1}^{*}$ to decrease by $1.513 \%-1.455 \%$. It is also observed that the value of $t_{1}^{*}, S^{*}, Q^{*}$, and $T C\left(t_{1}^{*}\right)$ all are moderately sensitive to the changes of $\beta$ for the considered inventory model.

By studying the results of Table 4 , it is found that $T C\left(t_{1}^{*}\right)$ coordinate to $c_{1}$, while the shortage time $t_{1}^{*}, S^{*}$, and $Q^{*}$ decrease as $c_{1}$ increases for the model. It is also found that $c_{1}$ increases from $8.3 \%$ to $150 \%, T C\left(t_{1}^{*}\right)$ decreases by $0.269 \%-$ $0.383 \%, Q^{*}$ decreases by $0.083 \%-0.058 \%, t_{1}^{*}$ decreases by $0.264 \%-0.181 \%$, and $S^{*}$ decreases by $0.203 \%-0.138 \%$, respectively. It is also observed that the values of $t_{1}^{*}, S^{*}, Q^{*}$, and $T C\left(t_{1}^{*}\right)$ all are lowly sensitive to the changes of $c_{1}$ for the considered inventory model.

By studying the results of Table 5 , it is found that $T C\left(t_{1}^{*}\right)$ coordinates to $c_{2}$, while $S^{*}, Q^{*}$, and $t_{1}^{*}$ decrease as $c_{1}$ increases for the model. It is also found that $c_{2}$ increases by $100 \%, T C\left(t_{1}^{*}\right)$ decreases by $0.269 \%-0.383 \%, Q^{*}$ decreases by $0.083 \%-0.058 \%, t_{1}^{*}$ decreases by $0.264 \%-0.181 \%$, and $S^{*}$ decreases by $0.203 \%-0.138 \%$.

By studying the results of Table 6 , it is found that $t_{1}^{*}, S^{*}$, $Q^{*}$, and $T C\left(t_{1}^{*}\right)$ coordinate to $c_{3}$. It is also observed that the value of $t_{1}^{*}, S^{*}, Q^{*}$, and $T C\left(t_{1}^{*}\right)$ all are lowly sensitive to the changes of $c_{3}$ for the inventory models; that is, $c_{3}$ increases from $1.9 \%$ to $3.2 \%$, the change of all the parameters is no more than $1 \%$.

By studying the results of Table 7 , it is found that $t_{1}^{*}, S^{*}$, $Q^{*}$, and $T C\left(t_{1}^{*}\right)$ coordinate to $c_{4}$. It is also observed that the value of $t_{1}^{*}, S^{*}, Q^{*}$, and $T C\left(t_{1}^{*}\right)$ all are lowly sensitive to the changes of $c_{4}$ for the inventory models; that is, $c_{4}$ increases from $14.3 \%$ to $100 \%$, the change of all the parameters is no more than $1 \%$.

\section{Conclusion}

An inventory model starting without shortage for Weibulldistributed deterioration with trapezoidal type demand rate and partial backlogging is considered in this paper. The optimal replenishment policy for the inventory model is proposed, and numerical examples are provided to illustrate the theoretical results. A sensitivity analysis of the optimal solution with respect to major parameters is also carried out. From Table 1-7, it can be found that the shortage time point $t_{1}^{*}$, order quantity $Q^{*}$, and the total average cost $T C\left(t_{1}^{*}\right)$ are moderately sensitive to the changes of $\alpha$ and $\beta$ and lowly sensitive to the changes of $\delta, c_{i}(i=1,2,3,4)$, respectively. The paper provides an interesting topic for further study, such that the joint influence from some of these parameters may be investigated to show the effects; the model starting with shortage will be studied and other types of models for deteriorating items in supply chain situation are also to be studied in the future.

\section{Conflict of Interests}

The author declares that there is no conflict of interests regarding the publication of this paper.

\section{Acknowledgments}

The author is grateful to the anonymous referees who provided valuable comments and suggestions to significantly improve the quality of the paper. This work was supported partly by Humanities and Social Science Fund of the Ministry of Education of China (no. 11YJCZH019).

\section{References}

[1] P. M. Ghare and G. F. Schrader, "A model for exponentially decaying inventories," Journal of Industrial Engineering, vol. 14, pp. 238-243, 1963.

[2] J.-W. Wu, C. Lin, B. Tan, and W.-C. Lee, "An EOQ inventory model with time-varying demand and Weibull deterioration with shortages," International Journal of Systems Science, vol. 31, no. 6, pp. 677-683, 2000.

[3] H.-M. Wee, "Deteriorating inventory model with quantity discount, pricing and partial backordering," International Journal of Production Economics, vol. 59, no. 1, pp. 511-518, 1999.

[4] K. Skouri and S. Papachristos, "A continuous review inventory model, with deteriorating items, time-varying demand, linear replenishment cost, partially time-varying backlogging," Applied Mathematical Modelling, vol. 26, no. 5, pp. 603-617, 2002.

[5] H.-M. Wee, J. C. P. Yu, and S. T. Law, “Two-warehouse inventory model with partial backordering and Weibull distribution deterioration under inflation," Journal of the Chinese Institute of Industrial Engineers, vol. 22, no. 6, pp. 451-462, 2005.

[6] C.-Y. Dye, T.-P. Hsieh, and L.-Y. Ouyang, "Determining optimal selling price and lot size with a varying rate of deterioration and exponential partial backlogging," European Journal of Operational Research, vol. 181, no. 2, pp. 668-678, 2007.

[7] R. M. Hill, "Inventory models for increasing demand followed by level demand," Journal of the Operational Research Society, vol. 46, no. 10, pp. 1250-1259, 1995.

[8] B. Mandal and A. K. Pal, "Order level inventory system with ramp type demand rate for deteriorating items," Journal of Interdisciplinary Mathematics, vol. 1, no. 1, pp. 49-66, 1998.

[9] K.-S. Wu, "An EOQ inventory model for items with Weibull distribution deterioration, ramp type demand rate and partial backlogging," Production Planning \& Control, vol. 12, no. 8, pp. 787-793, 2001.

[10] B. C. Giri, A. K. Jalan, and K. S. Chaudhuri, "Economic order quantity model with Weibull deterioration distribution, shortage and ramp-type demand," International Journal of Systems Science, vol. 34, no. 4, pp. 237-243, 2003.

[11] S. K. Manna and K. S. Chaudhuri, "An EOQ model with ramp type demand rate, time dependent deterioration rate, unit production cost and shortages," European Journal of Operational Research, vol. 171, no. 2, pp. 557-566, 2006.

[12] K. Skouri, I. Konstantaras, S. Papachristos, and I. Ganas, "Inventory models with ramp type demand rate, partial backlogging and Weibull deterioration rate," European Journal of Operational Research, vol. 192, no. 1, pp. 79-92, 2009. 
[13] K.-C. Hung, "An inventory model with generalized type demand, deterioration and backorder rates," European Journal of Operational Research, vol. 208, no. 3, pp. 239-242, 2011.

[14] R. S. Kumar, S. K. De, and A. Goswami, "Fuzzy EOQ models with ramp type demand rate, partial backlogging and time dependent deterioration rate," International Journal of Mathematics in Operational Research, vol. 4, no. 5, pp. 473-502, 2012.

[15] M. B. Cheng, B. X. Zhang, and G. Q. Wang, "Optimal policy for deteriorating items with trapezoidal type demand and partial backlogging," Applied Mathematical Modelling, vol. 35, no. 7, pp. 3552-3560, 2011.

[16] R. Uthayakumar and M. Rameswari, "An economic production quantity model for defective items with trapezoidal type demand rate," Journal of Optimization Theory and Applications, vol. 154, no. 3, pp. 1055-1079, 2012.

[17] Y. Tan and M. X. Weng, "A discrete-in-time deteriorating inventory model with time-varying demand, variable deterioration rate and waiting-time-dependent partial backlogging," International Journal of Systems Science, vol. 44, no. 8, pp. 14831493, 2013.

[18] M. A. Ahmed, T. A. Al-Khamis, and L. Benkherouf, "Inventory models with ramp type demand rate, partial backlogging and general deterioration rate," Applied Mathematics and Computation, vol. 219, no. 9, pp. 4288-4307, 2013.

[19] K.-P. Lin, "An extended inventory models with trapezoidal type demands," Applied Mathematics and Computation, vol. 219, no. 24, pp. 11414-11419, 2013.

[20] P. L. Abad, "Optimal pricing and lot-sizing under conditions of perishability and partial backordering," Management Science, vol. 42, no. 8, pp. 1093-1104, 1996. 


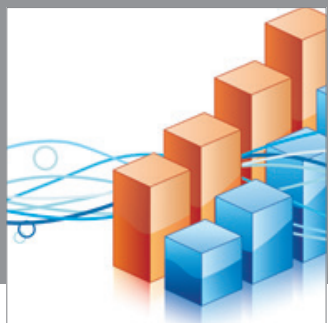

Advances in

Operations Research

mansans

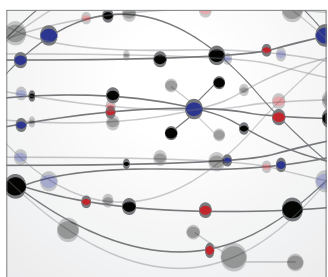

The Scientific World Journal
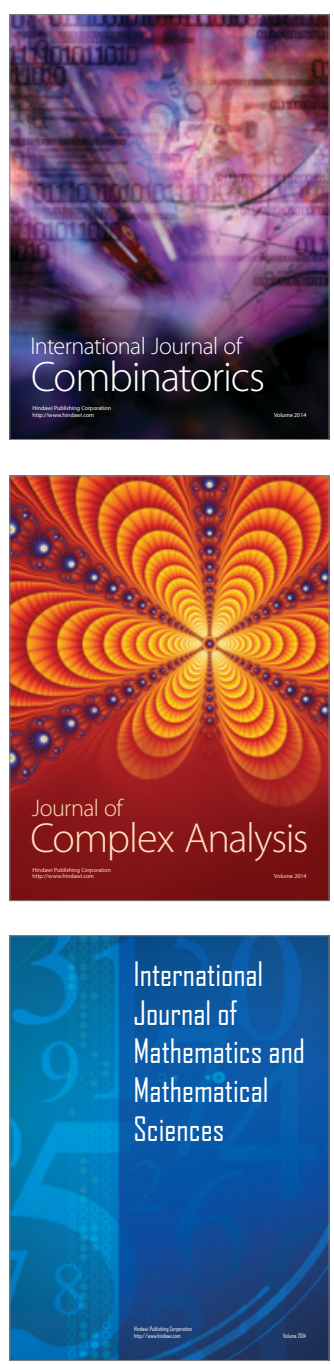
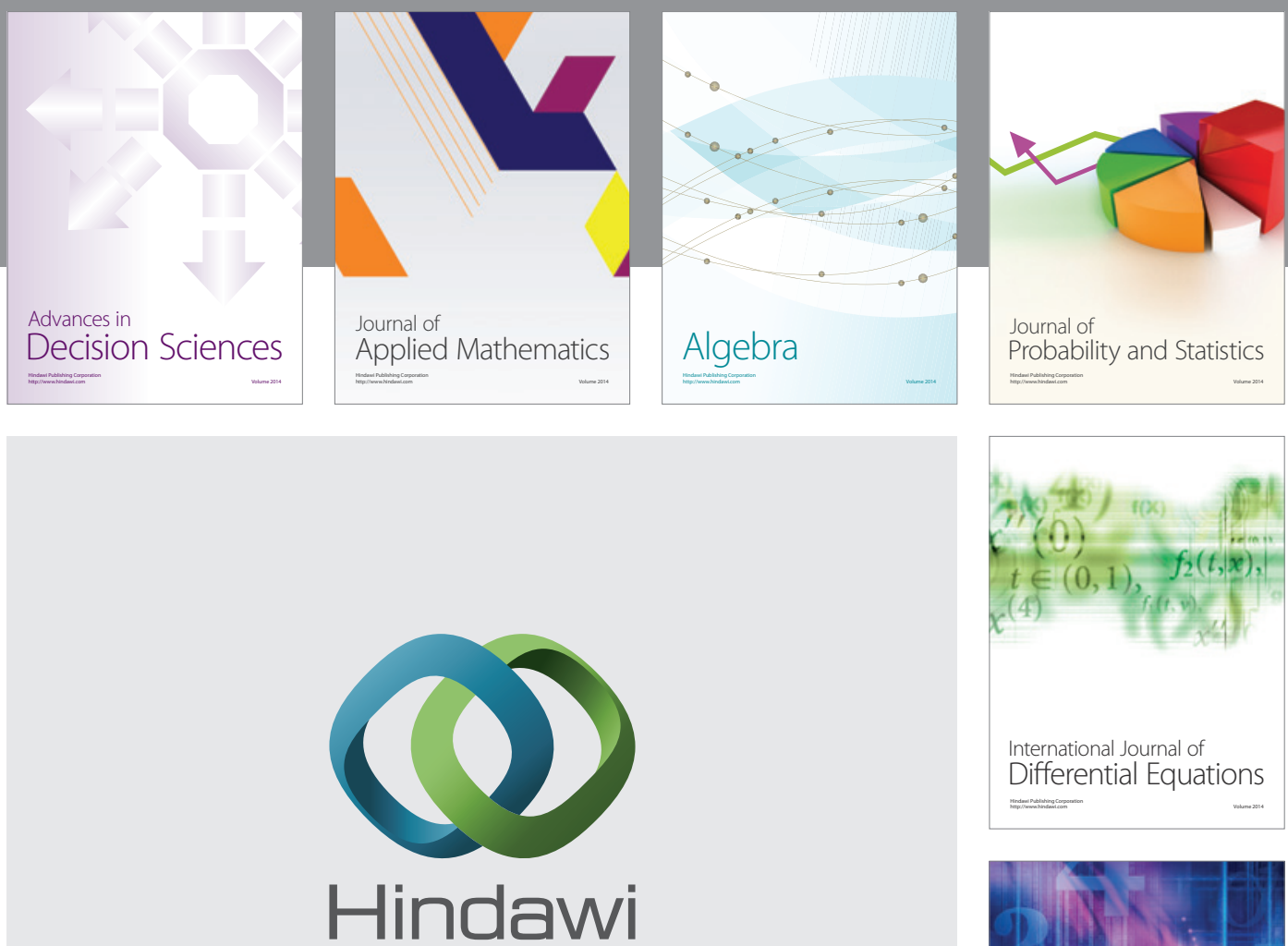

Submit your manuscripts at http://www.hindawi.com
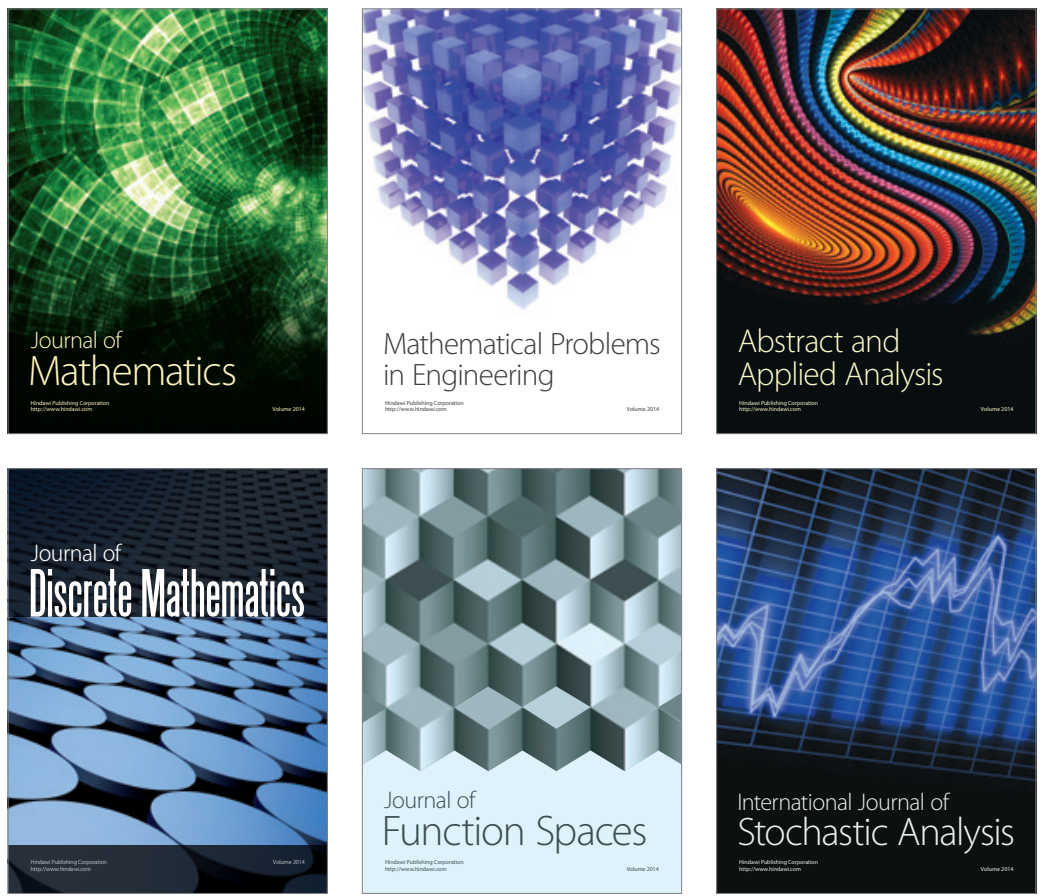

Journal of

Function Spaces

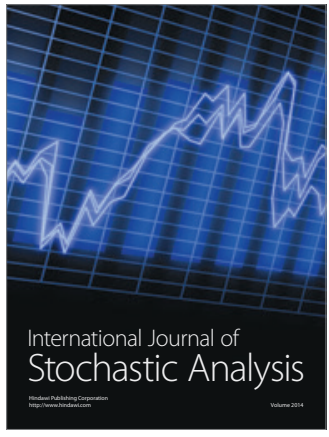

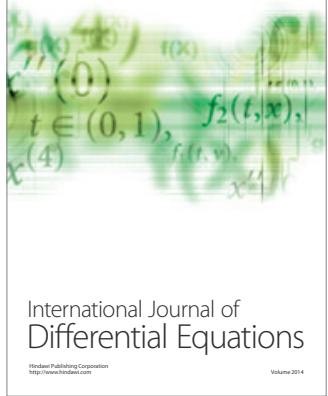
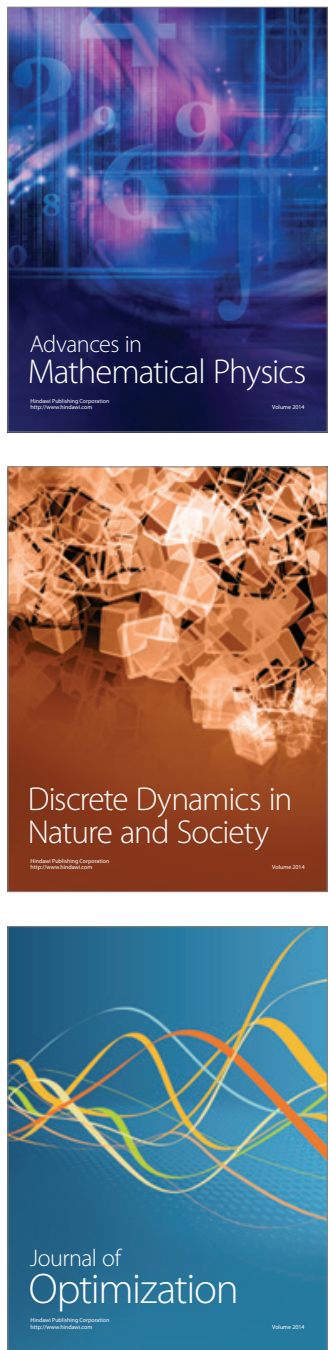